\title{
Development of sedimentary basins: differential stretching, phase transitions, shear heating and tectonic pressure
}

\author{
Ebbe H. Hartz, ${ }^{*}, \uparrow$ Sergei Medvedev $\uparrow$ and Daniel W. Schmid,$+ \S$ \\ *Det norske oljeselskap, Oslo, Norway \\ $\dagger$ Centre for Earth Evolution and Dynamics, Oslo University, Oslo, Norway \\ $\$$ Physics of Geological Processes, Oslo University, Oslo, Norway \\ $\S$ GeoModelling Solutions, Zurich, Switzerland
}

\begin{abstract}
Classical models of lithosphere thinning predict deep synrift basins covered by wider and thinner post-rift deposits. However, synextensional uplift and/or erosion of the crust are widely documented in nature (e.g. the Base Cretaceous unconformity of the NE Atlantic), and generally the post-rift deposits dominate basins fills. Accordingly, several basin models focus on this discrepancy between observations and the classical approach. These models either involve differential thinning, where the mantle thins more than the crust thereby increasing average temperature of the lithosphere, or focus on the effect of metamorphic reactions, showing that such reactions decrease the density of lithospheric rocks. Both approaches result in less synrift subsidence and increased postrift subsidence. The synextensional uplift in these two approaches happens only for special cases, that is for a case of initially thin crust, specific mineral assemblage of the lithospheric mantle or extensive differential thinning of the lithosphere. Here, we analyse the effects of shear heating and tectonic underpressure on the evolution of sedimentary basins. In simple 1D models, we test the implications of various mechanisms in regard to uplift, subsidence, density variations and thermal history. Our numerical experiments show that tectonic underpressure during lithospheric thinning combined with pressure-dependent density is a widely applicable mechanism for synextensional uplift. Mineral phase transitions in the subcrustal lithosphere amplify the effect of underpressure and may result in more than $1 \mathrm{~km}$ of synextensional erosion. Additional heat from shear heating, especially combined with mineral phase transitions and differential thinning of the lithosphere, greatly decreases the amount of synrift deposits.
\end{abstract}

\section{INTRODUCTION}

McKenzie's (1978) highly influential study 'Some remarks on basin formation' explains how extensional basins evolve in two phases. First rapid stretching and thinning of the lithosphere (and most importantly, its crustal part) forms the synrift part of a basin. The second part includes contraction of the lithospheric rocks as they cool towards thermal re-equilibration, which causes thermal subsidence of the lithosphere and formation of the post-rifting part of a basin. The concepts of synrift sedimentation, often associated with normal faulting, and post-rift sedimentation, guided by thermal subsidence, have been applied worldwide (see review in Ziegler \& Cloetingh, 2004), and represent the basic consensus and numerical basis in most basin models implemented in petroleum exploration (e.g. Hantschel \& Kauerauf, 2009).

Correspondence S. Medvedev, CEED, University of Oslo, P.O.Box 1028, 0316, Oslo, Norway. E-mail: sergei.medvedev@, geo.uio.no
Although the simple McKenzie (1978) model can predict qualitatively the evolution and structure of basins, the quantitative predictions often fail (Ziegler \& Cloetingh, 2004). A typical observation is that the rift episodes are not accompanied by significant synrift subsidence and the basins are dominated by post-rift sediments (Royden \& Keen, 1980; Sclater et al., 1980; Beaumont et al., 1982; Spadini et al., 1997; Walker et al., 1997). A second common observation is that rifting is immediately followed or partly synchronous with surface uplift. A prominent example of this is the Base Cretaceous unconformity in the North Atlantic (Surlyk, 1991; Brekke et al., 2001; Hartz et al., 2001; Kyrkjebø et al., 2004). This superregional erosional unconformity marks the end of rifting, and thus uplift at a time where classic models of passive rifting suggest the most rapid subsidence. In the NE Atlantic synextentional uplift is repeated during Late Cretaceous-Palaeocene rifting (Ren et al., 2003). A third discrepancy can be inferred from close inspections of subsidence curves published in several areas (White \& McKenzie, 1988; Gabrielsen et al., 2001; Ziegler \& 
Cloetingh, 2004) that suggest that subsidence accelerates during post-rifting phase (Middleton, 1980; Hamdani et al., 1994), at a time where classic models suggest that subsidence should slow down.

Figure 1 illustrates these three points. The thin Jurassic synrift is overlain unconformably by massive amounts of Cretaceous post-rift. The Base Cretaceous unconformity indicates that the late synrift was eroded before the post-rift was deposited. The case is even more extreme for late Cretaceous rift, which essentially did not leave a trace apart from a massive post-rift package.

In this study we elaborate on two approaches that have been developed to explain these phenomena, either discussing the effects of differential thinning (e.g. Royden \& Keen, 1980; Beaumont et al., 1982; Rowley \& Sahagian, 1986) or mineral phase transitions within the lithosphere (e.g. Podladchikov et al., 1994; Yamasaki \& Nakada, 1997; Petrini et al., 2001; Kaus et al., 2005; Simon \& Podladchikov, 2008).

Models focusing on differential thinning advocate that the crust is less thinned than the underlying lithospheric mantle. The effect of differential thinning is that the amount of synrift sediments is reduced by the counter effect of the additional buoyancy of the hot lithospheric mantle and elevated asthenosphere. Consequently, postrift sediments dominate, as the increased thermal perturbation of the sub-crustal mantle in the synrift leads to subsequent increased thermal subsidence. Such models either suggest that a major low-angle extensional detachment separates the less stretched crust and the highly thinned mantle (Wernicke, 1985) or, alternatively, the models focus on the 'steer-head' geometry of rift basins, where the post-rift basin covers a far wider area than the rift. These contributions advocate that the mantle is stretched over a wider area, which thereby will subside beyond the rift by widespread thermal subsidence (White \& McKenzie, 1988).

Mineral phase transitions have a strong effect on the evolution of basins given that minerals in the mantle may significantly decrease their density as pressure drops in thinned lithosphere and temperature increase (Podladchikov et al., 1994; Yamasaki \& Nakada, 1997; Petrini et al., 2001; Kaus et al., 2005; Simon \& Podladchikov, 2008). The decreasing density of the mantle lower the lithospheric weight, causing additional isostatic uplift, decreasing the package of the synrift sediments and increasing the post-rift package (Petrini et al., 2001; Simon \& Podladchikov, 2008). In some extreme cases the models can even result in synrift uplift (Kaus et al., 2005).

Most of the above-mentioned studies consider 1D basin formation. Additional theoretical work was done with 2- and 3-D analytical and numerical models that bring the understanding to a new level considering, for example, flexural and brittle behaviour of lithosphere (e.g. Braun \& Beaumont, 1989; Weissel \& Karner, 1989; Huismans \& Beaumont, 2002; Pérez-Gussinyé et al., 2006; Burov \& Gerya, 2014) and applying the models to real examples (e.g. Ebinger et al., 1991; Wolfenden et al., 2005; Pérez-Gussinyé et al., 2006). To identify key processes of basin evolution and reduce number of variables, we concentrate on 1D modelling.

We also exclude two processes that may change the style of basin evolution dramatically. Active rifting

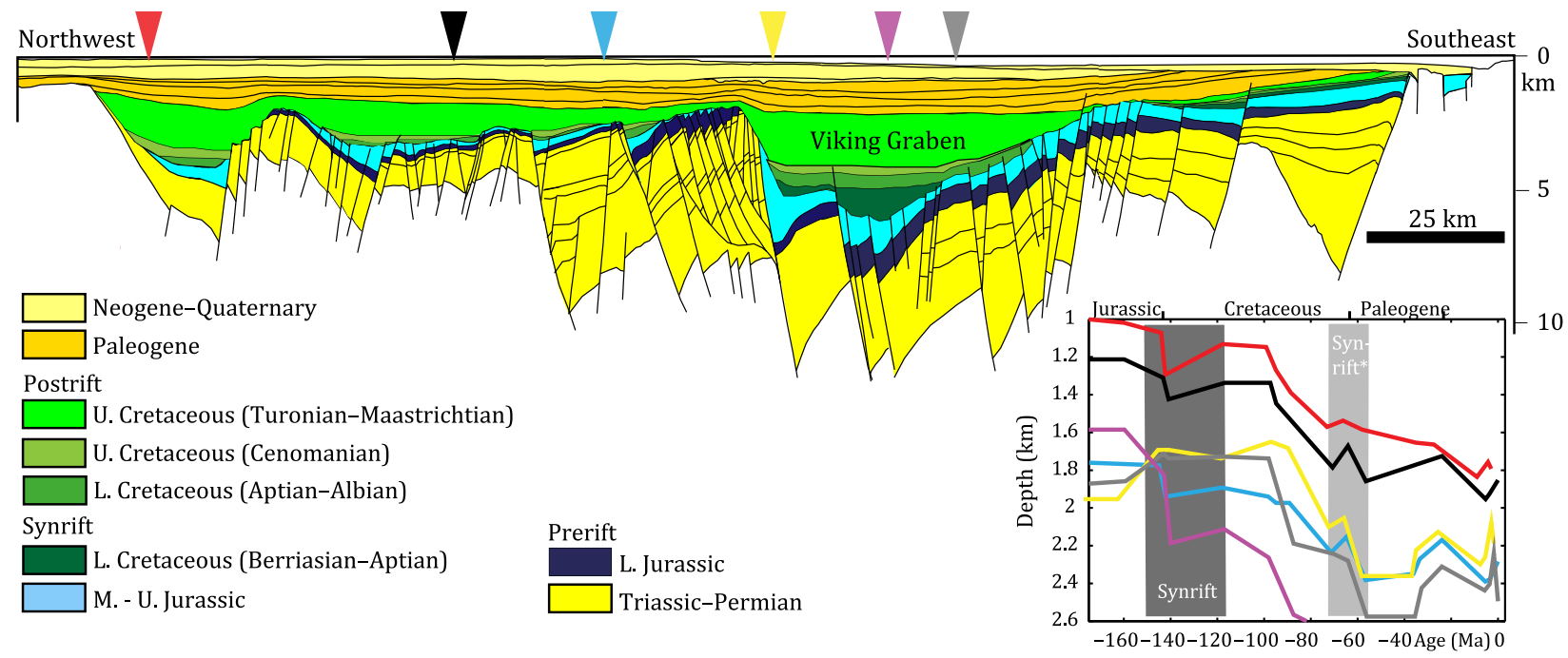

Fig. 1. Profile across the Viking graben of northern North Sea (modified from Christiansson et al., 2000). The onset of the main rifting event is somewhat enigmatic, but the sedimentary packages clearly grow in the Upper Jurassic and faults generally die out in the Lower Cretaceous. Sediments older than this are referred to as prerift, and sediments younger are referred to as post-rift. A later, Palaeogene, rifting limits the duration of the post-rift sequence. The synrift sequence is significantly thinner than the post-rift sediment package, with a thickness ratio of $\lambda<0.5$ for most of the cross-section. Significant erosion is marked by the Base Cretaceous unconformity below the post-rift sequence. This is also evident from the subsidence curves for several synthetic wells (inlet, modified from Gabrielsen et al., 2001). The well positions are marked by triangles with corresponding colours on the top of the profile. The duration of the main rifting event and the later Palaeogene rifting are marked by darker and lighter grey boxes correspondingly. 
involving significant additional heat flux from mantle and melting of the lithosphere denominates some natural rift systems, as, for example, the East African Rift System (Ziegler \& Cloetingh, 2004; Wolfenden et al., 2005; Keir et al., 2009). Serpentinisation of the uppermost mantle controls other natural systems, as, for example, the hyperextended Iberian margin (Pérez-Gussinyé et al., 2006; Peron-Pinvidic et al., 2013). These two effects require special thermal and pressure conditions and fluid availability (Ulmer \& Trommsdorff, 1995; Pérez-Gussinyé et al., 2001; Herzberg et al., 2010). Our study is deliberately not designed to reach these extreme conditions and applies to more general situations.

In our study we attempt to find simple causes for the three phenomena that contrast classic subsidence models (McKenzie, 1978): (i) synrift uplift, (ii) domination of post-rift sediments in extensional basins and (iii) post-rift acceleration of subsidence. We also analyse how these departures from the classical model affect the petroleum potential of sedimentary basins.

\section{MODEL}

\section{Model formulation}

The temperature evolution is computed based on the energy balance in a 1D Lagrangian system

$\rho c_{\mathrm{p}} \frac{\partial T}{\partial t}=\frac{\partial}{\partial z}\left(k \frac{\partial T}{\partial z}\right)+Q$

where $T=T(z, t)$ is the unknown temperature that depends on the Lagrangian coordinate $z$ and time $t ; \rho$ is the density, $c_{p}$ is the heat capacity and $k$ is thermal conductivity. $Q$ is a heat source related to the radioactive heat production, $A$, and the dissipation caused by shear heating:

$Q=A+\dot{\varepsilon} \sigma_{\text {tectonic }}$

$\dot{\varepsilon}$ is the strain rate, and $\sigma_{\text {tectonic }}$ is the tectonic stress (Hartz \& Podladchikov, 2008) that is required to deform the lithosphere. During the phase of active deformation, we specify $\dot{\varepsilon}$ in terms of deformation in Lagrangian coordinates:

$\frac{\partial^{2} Z}{\partial z \partial t}=\dot{\varepsilon}-\frac{1}{\rho} \frac{\partial \rho}{\partial t}$

meaning that the rate of relative change in any small segment with the vertical coordinate $Z$ in the lithosphere depth equals to the prescribed strain rate minus the relative density change. The first term in the right-hand side specifies the prescribed kinematics, the second term controls mass conservation in the system. The tectonic stress in eqn. (2) is calculated using power-law viscous rheology for lithospheric rocks and Byerlee's friction law (Byerlee, 1978):

$\sigma_{\text {tectonic }}=\min \left[2 \mu\left(I_{2}, T\right) \dot{\varepsilon} ; \sigma_{\text {Byerlee }}(P)\right]$

where the effective viscosity $\mu$ is a power-law function of the second invariant of the strain-rate tensor $I_{2}$ and an exponential function of temperature. The Byerlee's stress $\sigma_{\text {Byerlee }}$ is a piece-wise linear function of the pressure $P$.

Pressure is related to the density structure in the lithosphere. The most simplified models assume that density depends linearly on temperature (e.g. McKenzie, 1978). More complex models also take into account a linear dependency on the pressure:

$\rho=\rho_{0}-\alpha_{\mathrm{T}}\left(T-T_{0}\right)+\alpha_{\mathrm{P}}\left(P-P_{0}\right)$

$\alpha_{\mathrm{T}}=3 \times 10^{-5} \mathrm{~K}^{-1} ; \quad \alpha_{\mathrm{P}}=10^{-11} \mathrm{~Pa}^{-1}$

where $\alpha_{T}$ is the thermal expansion coefficient, $\alpha_{P}$ is rock compressibility and $T_{0}$ and $P_{0}$ are the conditions at which the reference density $\rho_{0}$ was measured. In reality the density of rocks undergoes rapid changes at phase and reaction boundaries that are controlled by temperature, pressure, composition and fluids. The latter introduce a large uncertainty concerning the density structure of the crust, which is why we consider here only mantle phase transitions (similar to Petrini et al., 2001; Kaus et al., 2005). To this end we use precomputed density maps $\rho=\rho(P, T)$ (Kaus et al., 2005; Simon \& Podladchikov, 2008).

An often made approximation for pressure is that it is equal to the lithostatic pressure:

$P_{\text {lithos }}(z)=\int_{z}^{S} \rho g \mathrm{~d} z$

where $S$ is the upper surface and $g$ is acceleration due to gravity. The lithostatic pressure is a good estimate for pressure under static conditions. In the deforming lithosphere, however, the total mechanical pressure deviates from the lithostatic (e.g. Schmalholz et al., 2014). Following Petrini \& Podladchikov (2000), we assume that the vertical normal stress is equal the lithostatic pressure, $\sigma_{\mathrm{zz}}=-P_{\text {lithos, }}$, and the horizontal normal stress is $\sigma_{x x}=-P_{\text {lithos }}+\sigma_{\text {tectonic }}$. The resulting pressure then is calculated for the 2D plane-strain case as:

$P=-\frac{\sigma_{x x}+\sigma_{z z}}{2}=P_{\text {lithos }}-\frac{\sigma_{\text {tectonic }}}{2}$

The difference between pressure and lithostatic pressure is usually termed 'overpressure' (Mancktelow, 2008; Schmalholz et al., 2014). In the context of this study where we consider extension it would be more appropriately termed 'underpressure', considering that this term makes absolute value of pressure smaller than lithostatic pressure (Fig. 2).

The original analytical solution of McKenzie (1978) was based on simplifications of the model described above, ignoring heat source term $Q$ in eqn. 1, assuming instantaneous thinning of the lithosphere (infinite strain rate in eqn. 3) and assuming density dependence on temperature only (cf. eqn. 5). Numerical approaches to the problem allow for more realistic parameters of the model, accounting for radioactive heat production (eqn. 2), finite strain rate of the active phase of rifting and density 


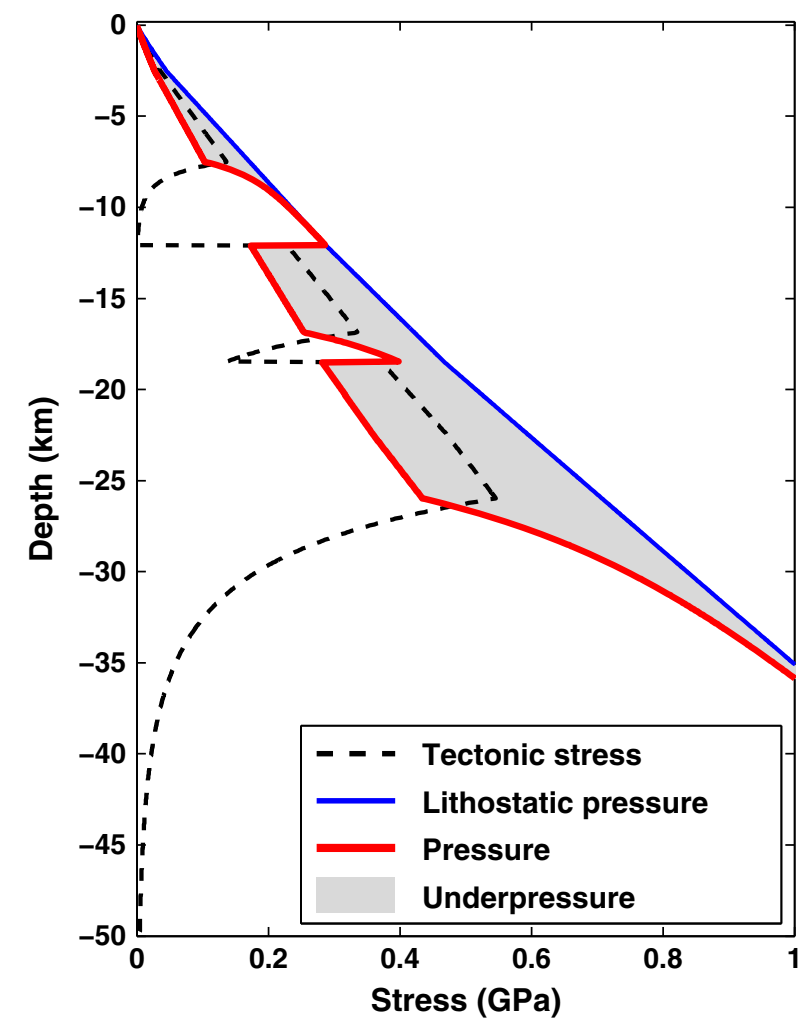

Fig. 2. Relation among tectonic stress (eqn. 4), lithostatic pressure (eqn. 6) and pressure (eqn. 7). Note that the pressure in our models can be significantly smaller than the lithostatic pressure.

depending on lithostatic pressure (eqns 5 and 6), and even models in which density accounts for mineral phase transitions. In the following we refer to these models as 'standard' (e.g. Petrini et al., 2001; Kaus et al., 2005). In terms of the above formulation (eqns 1-7), these standard models ignore shear heating in the balance of energy (eqns 1 and 2) and use lithostatic pressure as approximation to pressure (eqns 6 and 7, Fig. 2). Furthermore, we compare the standard models with 'mechanical' models, in which we implement and analyse shear heating and tectonic pressure. Note that this approach is based on the quantification of the stresses involved (eqn. 4) and, thus, in contrast with most of previously used 1D conceptual models of basin evolution, relies on the rheological properties of the lithospheric materials.

\section{Numerical implementation and setup}

Our calculations are performed using updated version of LiToastPhere, originally developed by Hartz \& Podladchikov (2008). The underlying numerical scheme is a 1D finite difference method. We use a Lagrangian approach that avoids explicit advection in a deforming domain. The deformation consists of two components: (i) the applied kinematic thinning, and (ii) the effect of local, Airy isostatic compensation. The grid spacing is variable to provide the highest resolution where required. We use 2500 3000 Lagrangian points spaced initially $50 \mathrm{~m}$ from each other in the top $120 \mathrm{~km}$ of the model lithosphere and less dense below. For each time step, the geometry is updated first with a prescribed strain rate (eqn. 3 with ignoring the density variations), then the temperature is updated (eqn. 1), then the geometry is updated again accounting for the density changes (eqn. 3 with ignoring the prescribed kinematics) and the system is adjusted to fulfil the isostasy condition (constant pressure at the compensation level of $120 \mathrm{~km}$ ) by vertical shifting and applying surface processes (sedimentation or/and erosion). In all presented models we apply an instantaneous sedimentation model, in which we fill the entire accommodation space as soon as the upper surface subsides below the sea level. In some models we also employ infinitely fast erosion where we instantly remove all material above sea level at any given time. Thus, even though the sediment density model assumes pores filled with water, the water depth is always zero.

The total model depth is $250 \mathrm{~km}$, has a surface temperature of $2{ }^{\circ} \mathrm{C}$ and an asthenospheric temperature of $1330{ }^{\circ} \mathrm{C}$ that is assigned to the mantle between 120 and $250 \mathrm{~km}$ depth (assuming that highly conductive asthenosphere has enough heat to support increased heat flux during rifting). Initially the model consists of four layers with rheological properties described in the corresponding references: the uppermost $18 \mathrm{~km}$ is the upper crust (wet quartz, Carter \& Tsenn, 1987), between 18 and $30 \mathrm{~km}$ is the lower crust (dry mafic granulite, Wilks \& Carter, 1990) and below $30 \mathrm{~km}$ is lithospheric mantle and asthenosphere (dry dunite, Chopra \& Paterson, 1981). The reference density $\rho_{0}$ (eqn. 3 ) for the layers described by eqn. 5 is $2600 \mathrm{~kg} \mathrm{~m}^{-3}$ (upper crust), $2900 \mathrm{~kg} \mathrm{~m}^{-3}$ (lower crust) and $3355 \mathrm{~kg} \mathrm{~m}^{-3}$ (lithospheric mantle and asthenosphere). Some of our models use nonlinear model density model in the mantle part of the model. The sediments are described by the rheological properties of wet quartz (Carter \& Tsenn, 1987) and the compaction model of Sclater \& Christie (1980) with a matrix density of $2300 \mathrm{~kg} \mathrm{~m}^{-3}$, surface porosity of 0.49 and a porosity decrease e-fold length of $3.7 \mathrm{~km}$. Given the expected depth of the resulting sedimentary basin $(7.2 \mathrm{~km})$, the density variations in sediments are in the range 1650$2200 \mathrm{~kg} \mathrm{~m}^{-3}$.

The heat capacity $c_{p}$ is $1000 \mathrm{~J} \mathrm{~kg}^{-1} \mathrm{~K}^{-1}$ for all the materials. The thermal conductivity $k$ is $3 \mathrm{~W} \mathrm{~m}^{-1} \mathrm{~K}^{-1}$ in all the layers except mantle part, where it is $4.5 \mathrm{~W} \mathrm{~m}^{-1} \mathrm{~K}^{-1}$. The radioactive heat production is $10^{-7} \mathrm{~W} \mathrm{~m}^{-3}$ for all layers except the upper crust and the sediments, where it is $10^{-6} \mathrm{~W} \mathrm{~m}^{-3}$.

The model is simplified in several aspects. Thus, even though we consider density variations in sediments, we ignore potential variations in rheological and thermal properties of sediments caused by porosity changes with depth. The numerical models presented below are designed to investigate the importance of the various modelled components. All models undergo two phases of evolution. The initial rift phase with a stretching rate of $\dot{\varepsilon}=4.5 \times 10^{-15} \mathrm{~s}^{-1}$ until the crust thinned by factor 
$\beta=2$ takes ca. $5 \mathrm{Myr}$ (the effects of variations in the rift duration are presented in the Discussion). The post-rift thermal relaxation is modelled for $180 \mathrm{Myr}$ to ensure thermal re-equilibration (well above $60 \mathrm{Myr}$, the time scale of thermal anomaly decay suggested in Jarvis \& McKenzie, 1980). If not specified otherwise, the models assume the uniform stretching of the entire lithosphere. We also present models with nonuniform stretching, characterised by parameter $\delta$, the ratio of strain rate in the mantle to strain rate in the crust.

Interestingly, all models result in an identical total sedimentary thickness of $7.2 \mathrm{~km}$. One reason for this is that we use a simplified single lithology infill. The other one is that variations in differential thinning, duration of active deformation and consideration of shear heating and underpressure are only of temporary importance but do not affect the final geometry of the crust and thermal steady state of the lithospheric mantle. In the case of models including mineral phase transitions slight adjustments $(<1 \%)$ had to be made to the published density models to obtain the same 7.2-km basin depth as for the models described by eqn. 5 . This was done to facilitate comparison between our models and can be justified given the uncertainty of mantle density structure.

The internal structure of modelled basins is, however, not the same for all the cases. We analyse the resulting sedimentary basins by calculating sediment ratio $\lambda$, the ratio of thicknesses of synrift to post-rift sediments at the end of the experiment. We also analyse the evolution of basin maturity based on the Easy\%Ro algorithm of Sweeney \& Burnham (1990).

\section{RESULTS \\ Standard models}

In this section we present the standard models, that is the ones that do not incorporate rheology-dependent mechanical components. We separate them into models that consider density that is linearly dependent on pressure and temperature (eqn. 5) and models that implement precomputed phase transitions for the mantle densities (e.g. Simon \& Podladchikov, 2008). Furthermore, we investigate the effect of differential thinning on all model configurations.

\section{Linear pressure dependence}

The effect of uniformly thinning the lithosphere to half its original thickness in a standard model with a density that is linearly dependent on pressure and temperature is shown in Fig. 3. Panel A illustrates the evolution on a lithospheric scale. The model undergoes thinning over the first $5 \mathrm{Myr}$, followed by a $180 \mathrm{Myr}$ long post-rift per-
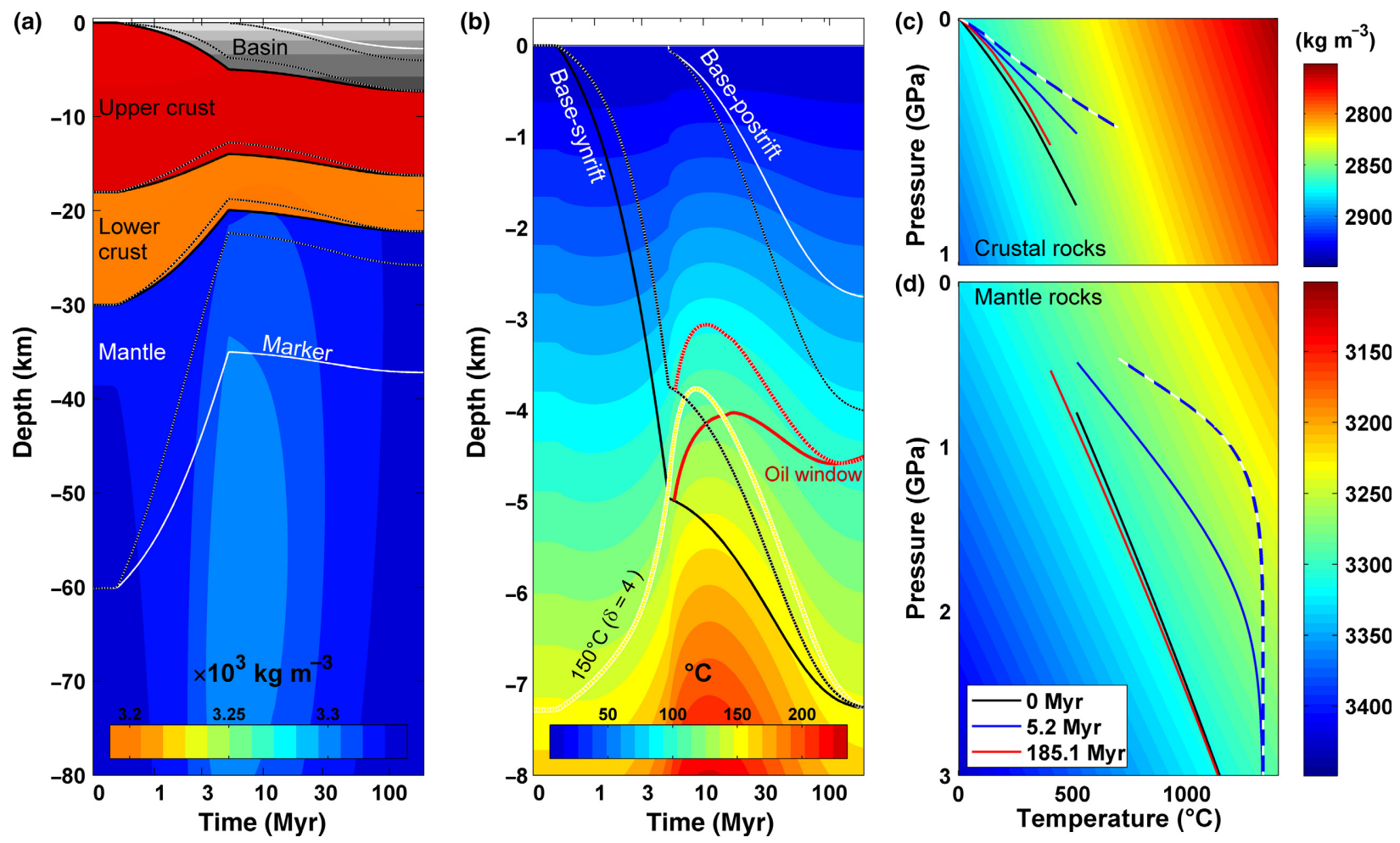

Fig. 3. Evolution of the model with linear dependence of density on pressure and temperature. The main plot and full lines illustrate uniform thinning $(\delta=1)$, whereas stippled lines marks differential thinning $(\delta=4)$. (a) Density evolution of the model. Shades of grey mark density changes in the basin due to compaction. The density of the mantle changes significantly and illustrated by the colour bar. (b) Thermal evolution of the upper $8 \mathrm{~km}$ of the crust. Red line marks oil window $(\rho=0.7)$. Yellow line is a $150{ }^{\circ} \mathrm{C}$ isotherm of the model with $\delta=4$. Right: Evolution of the crust (c) and subcrustal lithosphere (d) in a pressure-temperature diagram, contoured with rock density 
iod that ensures thermal equilibrium at the end of calculations. As the timescales of syn- and post-rift are different we use a logarithmic scale to better capture their details.

One of the main effects of the rifting is a significant heating of the model. This can be inferred from panels $\mathrm{C}$ and $\mathrm{D}$ where we plot the pressure and temperature state of the crust and mantle parts of the domain correspondingly. The blue lines show the state right at the end of the synrift, which is substantially hotter than the initial and the final pressure and temperature state. Due to this heating the rock densities in the model are reduced, which reduces the synrift subsidence and causes the post-rift subsidence when the rocks cool and contract again. Note that the density variations in the crust are only minor (20 $30 \mathrm{~kg} \mathrm{~m}^{-3}$ ) because of the limited thickness of the crust. Variations in density in the sub-crustal lithosphere are much greater (hundreds of $\mathrm{kg}$ ) and thus these variations dominate the evolution of the lithospheric column.

A zoom into the uppermost part of the model is shown in panel B where we plot the temperature field of the upper crust and the developing sedimentary basin together with the evolution of the sediment-basement interface, the interface between synrift and post-rift sediments and the oil window indicator. The latter is computed based on the Easy\%Ro algorithm of Sweeney \& Burnham (1990) and assigned to a synthetic vitrinite value of 0.7 . The temperature field shows that the initial $(0$ $2 \mathrm{Myr}$ ) response to rifting in the uppermost part of the model is minor cooling. This is related to the rapid sedimentation of relatively cold sediments (thermal blanketing, Wangen, 1995). This phase of cooling is then followed by a phase of heating, which is driven by the overall heating of the system during the synrift. However, only towards the end of the synrift has the heat from below propagated far enough to start to affect the sediments. In fact, the phase of elevated sediment temperatures is mostly related to the early post-rift. This sediment heating is also seen on the oil window curve. The Ro 0.7 value is reached by the deepest synrift sediments right at the beginning of the post-rift at a depth of ca. $5 \mathrm{~km}$. The additional heat from below reduces the depth of the oil window to $c a .4 \mathrm{~km}$. With the thermal relaxation of the model system the oil window becomes eventually controlled by burial and is finally located at $c a$. $4.5 \mathrm{~km}$ depth. As expected from a McKenzie (1978) type model the bulk of the sediments are deposited in the synrift. The synrift to post-rift sediment thickness ratio is $\lambda=1.7$. A model with infinitely fast rifting, that is a close analogue of the original McKenzie (1978) model, would result in $\lambda=1.6$, whereas models with slower rifting (duration of rifting more than $11 \mathrm{Myr}$ ) result in $\lambda>2$.

Superposed on the plots for the uniform stretching model we also show some key results from a differential stretching model where we stretch the mantle four times more than the crust $(\delta=4)$. As the mantle is thinned more, the asthenosphere-lithosphere boundary is advected closer to the surface and the model is overall hotter. This can be seen with the white-blue dashed lines on panel $\mathrm{D}$ as well with the $150^{\circ} \mathrm{C}$ isotherm on panel $\mathrm{B}$. The consequence is that the densities are reduced even more than in the models with uniform stretching, whereas the system is at elevated temperatures, which leads to a reduced synrift. High elevation of temperature during synrift leads to more significant post-rift relaxation and an increased amount of post-rift sediments. The sediment ratio $\lambda$ is 0.83 . The oil window is again reached by the deepest synrift sediments at the beginning of the post-rift, albeit at a depth of only $c a .3 .7 \mathrm{~km}$. Similar to the uniform stretching model the sediments are at elevated temperatures in the early post-rift, whereas the final stages are controlled by burial. The final sediment thickness and depth of the oil window are identical to the uniform stretching model. The reason for this is that the altered temperature state due to the differential stretching is only of transient nature and we use a simplified basin infill. If we would use a heterogeneous basin infill with different properties especially in the synrift and the post-rift, then differences could be observed between the different models, but these are not the focus of this contribution where we investigate only first-order effects.

\section{Mineral phase transitions}

The results of the uniform stretching standard model with mineral phase transitions in the mantle are shown in Fig. 4. Similar to previous models, we utilise the linear density model for the crust which is reflected in the smooth density plot (C), whereas the mantle densities (D) show sharp jumps across phase boundaries. The phase diagram used here is the Hawaiian pyrolite of Simon \& Podladchikov (2008) and the mantle density jumps take place when the peridotite shifts from the stability conditions of garnet (densest) through spinel to plagioclase (lightest).

The consequence of using a more realistic model for the mantle densities is shown in panel $\mathrm{A}$, which illustrates the complexity of the mantle density state in space and time. Compared to the linear pressure dependence model, this results in reduced densities and, thus, in reduced subsidence in the synrift and early post-rift. The sediment ratio is $\lambda=0.77$, which is less than the one with linear pressure-dependent model with differential thinning $(\lambda=0.83$, Fig. 3$)$. The oil window in this model is reached only far into the post-rift ( $c a .10 \mathrm{Myr})$, that is towards the end of the rifting-related sediment heating period. Together with the more rapid (late) post-rift subsidence, the result is that we observe no temporary shallowing of the oil window.

Introducing differential thinning into this model with mineral phase transitions results in a further reduction in the synrift subsidence, with $\lambda=0.19$. The main reason for this is that substantial parts of the mantle are hot enough to be in the plagioclase stability field (see panel D). Due to the reduced synrift sedimentation the oil window is shifted farther into the post-rift and reached by deepest sediments only at $c a$. $25 \mathrm{Myr}$. This is the first 

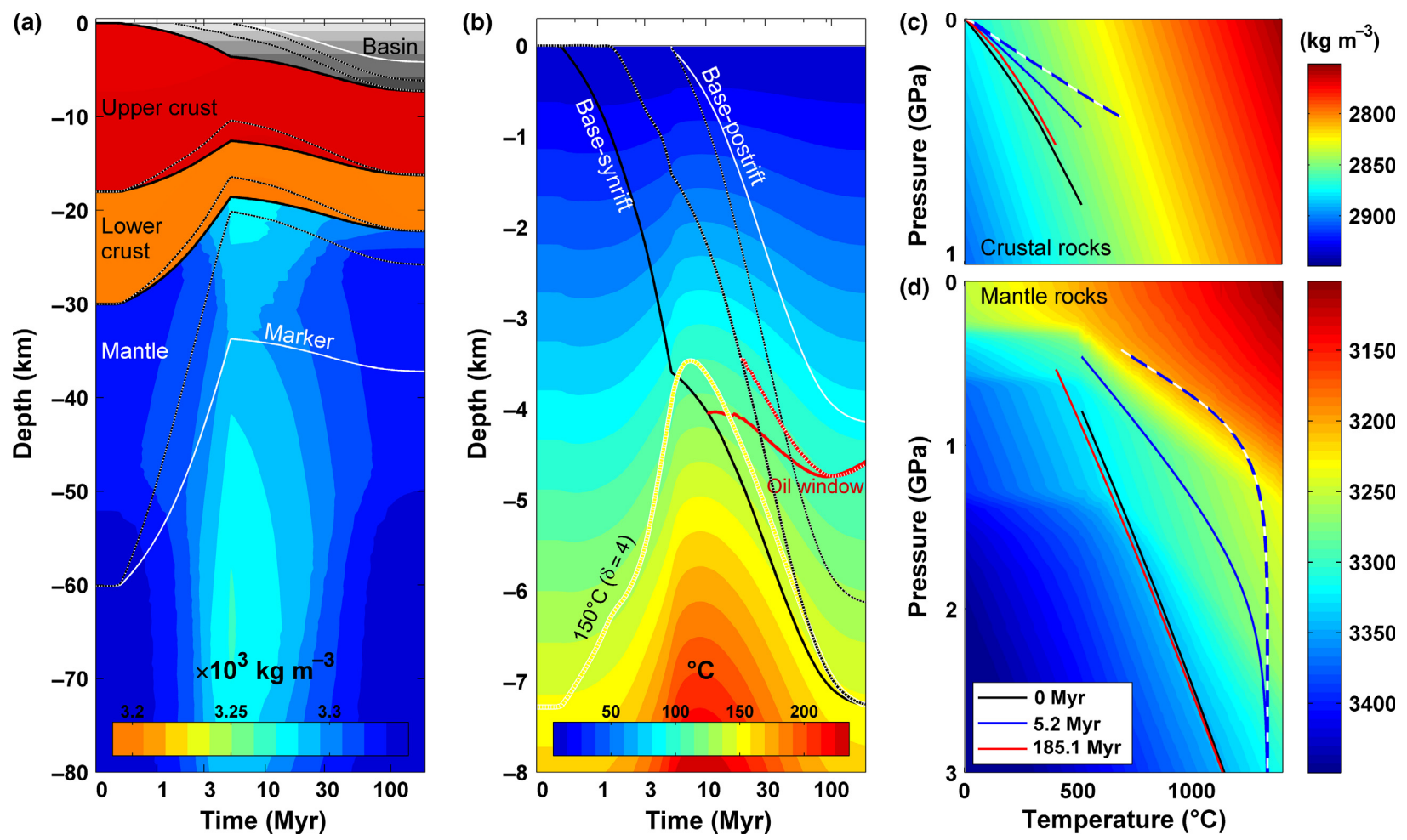

Fig. 4. Evolution of the model with mantle density (d) controlled by mineral phase transitions. See Fig. 3 for other details of design.

model in our series of experiment where we observe a minor $(3 \mathrm{~m})$ synrift uplift. As it is so small it does not result in a substantial uplift even if erosion is activated.

\section{Mechanical models}

In this section we repeat the set of standard model with the added mechanical effects. Based on the rheological parameters of the model and rate of extension, we compute shear heating and pressure that is based on stress that includes the tectonic component. For the prescribed strain rate and rheological parameters of the model we compute the tectonic stress required for deformation (eqn. 4). The stress then is used to calculate the shear heating term in the energy balance (eqns 1 and 2) and to calculate the underpressure part of pressure (eqn. 7).

\section{Linear pressure dependence}

The results of considering the mechanical effects in a uniform stretching model with density depending linearly on pressure and temperature are shown in Fig. 5. The pressure-temperature-density pathway (panels C and D) is considerably more complex compared to the standard models. The main cause for this is the development of underpressure during the phase of active deformation, which results in decreased pressure in the strongest parts of the crust and mantle by $0.2-0.3 \mathrm{GPa}$. Shear heating brings an additional rise of temperature in the system by ca. $30-40{ }^{\circ} \mathrm{C}$ around the strongest parts of the crust and mantle. The consequence is that the densities during rifting are reduced resulting in less synrift sediments. The sediment thickness ratio is $\lambda=1.44$, decreased from the value of 1.7 in the standard model. Despite the complex pressure-temperature-density evolution during the synrift, this model is altogether quite similar to the corresponding standard model. The same holds when we introduce differential thinning into the mechanical model.

One notable difference compared to the standard models is that the uniform and differential stretching mechanical models result in a synrift uplift of 110 and $130 \mathrm{~m}$, respectively. If we, in addition, activate erosion then the corresponding uplift amounts are substantial, that is 620 and $670 \mathrm{~m}$. This amplification of the uplift by erosion is caused by the equilibration of the modelled lithospheric column due to local isostasy. Interestingly, the synrift to post-rift sediment thickness ratio is almost unaffected by the erosion. This is because the uplift and erosion occur in the early phases of rifting, which leaves the erosion models enough time to deposit a similar amount of synrift sediments, compared to models without erosion. Note though that in the case of active erosion the total subsidence is different than in all other models $(7.4 \mathrm{~km}$ vs $7.2 \mathrm{~km}$ in the models without erosion) as the removal of crust leads to an altered isostatic balance. This makes model comparison more difficult, which is why we do not report further details of the erosion models.

\section{Mineral phase transitions}

Both, shear heating and tectonic underpressure change the PT conditions in the lithosphere. Thus, when combined with MPT the effect on the basin evolution is dramatic (Fig. 6). The model is characterised by significantly smaller 

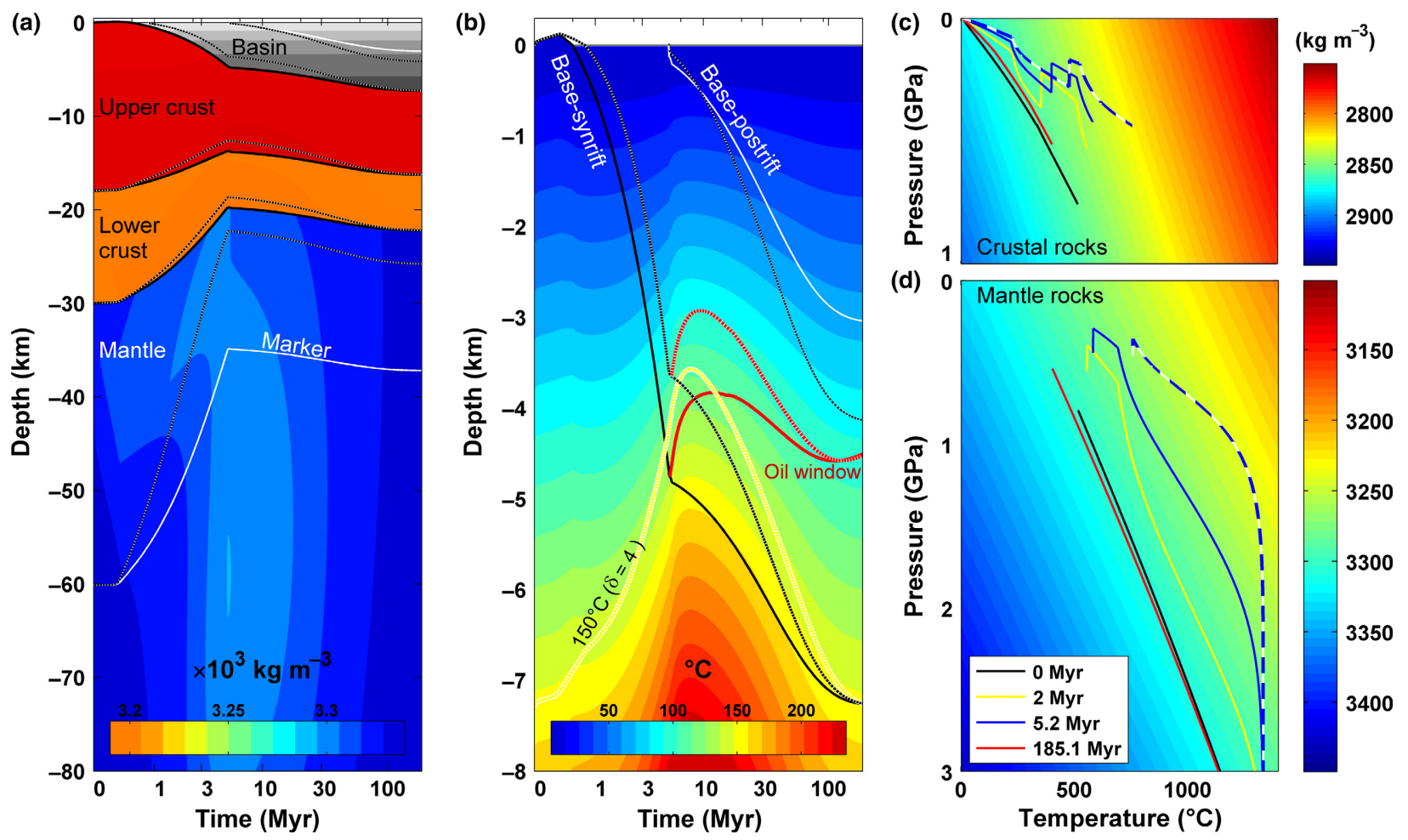

Fig. 5. Evolution of the mechanical model with linear dependence of density on temperature and pressure. See Fig. 3 for other details of design.

thickness of the synrift package and, correspondingly, a smaller $\lambda=0.48$. The model also demonstrates uplift during initial phase of up to $200 \mathrm{~m}$. When combined with erosion this uplift is amplified to $1150 \mathrm{~m}$.

Introducing differential thinning to this model results in lowered pressures in the mantle during the synrift and an overall additional heat input during the synrift and early post-rift. The synrift to post-rift package thickness ratio is reduced to 0.16 , that is there is almost no synrift record in the sediment sequence. The uplift without erosion is $280 \mathrm{~m}$, which is amplified to $1850 \mathrm{~m}$ when erosion is active. The uplift in this model extends over most of the synrift.

\section{DISCUSSION}

The classical McKenzie (1978) model explains rift basins that are characterised by a dominant synrift and a minor post-rift package and shows a continuous subsidence, that is no uplift. As discussed in the Introduction, many basins do not conform to this model. Table 1 summarises our results and shows that including more relevant physics yields models that differ substantially from the McKenzie model.

\section{Synrift to post-rift sediment thickness ratio, $\lambda$}

The dominance of the synrift sediment thickness package is restricted to models that include neither differential thinning nor mineral phase transitions. Resolving the lat- ter two processes results in basins that show a larger postrift than synrift package (Fig. 7A,B). Accounting for the mechanical effects further reduces $\lambda$, but only by a moderate amount (Fig. 7C).

Assuming uniform stretching the most extreme synrift to post-rift thickness ratio $\lambda$ is 0.48 (Table 1 , experiment $\mathrm{f}$ in Fig. $7 \mathrm{C}$ ), which results from the mechanical model with mantle phase transitions, that is the post-rift is twice as thick as the synrift. Assuming differential thinning with $\delta=4$ but no mineral phase transitions results in $\lambda=0.83$ if mechanical effects are not included (experiment $\mathrm{c}$ in Fig. 7B). Combining these two scenarios, that is differential thinning and mineral phase transitions, results in a ratio of 0.16 , that is a basin that is almost entirely filled with post-rift sediments (Table 1).

We observe that the most important parameter reducing the synrift package is the inclusion of mineral phase transition mantle density maps. Different maps have been proposed over time. Kaus et al. (2005) calculated a map for the Hawaiian pyrolite that showed relatively extreme effects (line 5 in Fig. 7). Simon \& Podladchikov (2008) published a whole suite of maps for different mantle compositions (lines 2-4 in Fig. 7). In our studies we use mainly the Hawaiian pyrolite of Simon \& Podladchikov (2008). As shown in Fig. 7 all phase transition mantle density maps exhibit similar effects on the synrift to postrift thickness ratio and the models presented in our 'Results' section bracket the series of other density maps.

Figure 7 also demonstrates the importance of an additional key parameter, the rift duration. With increasing duration of the rift the synrift sediment thickness 

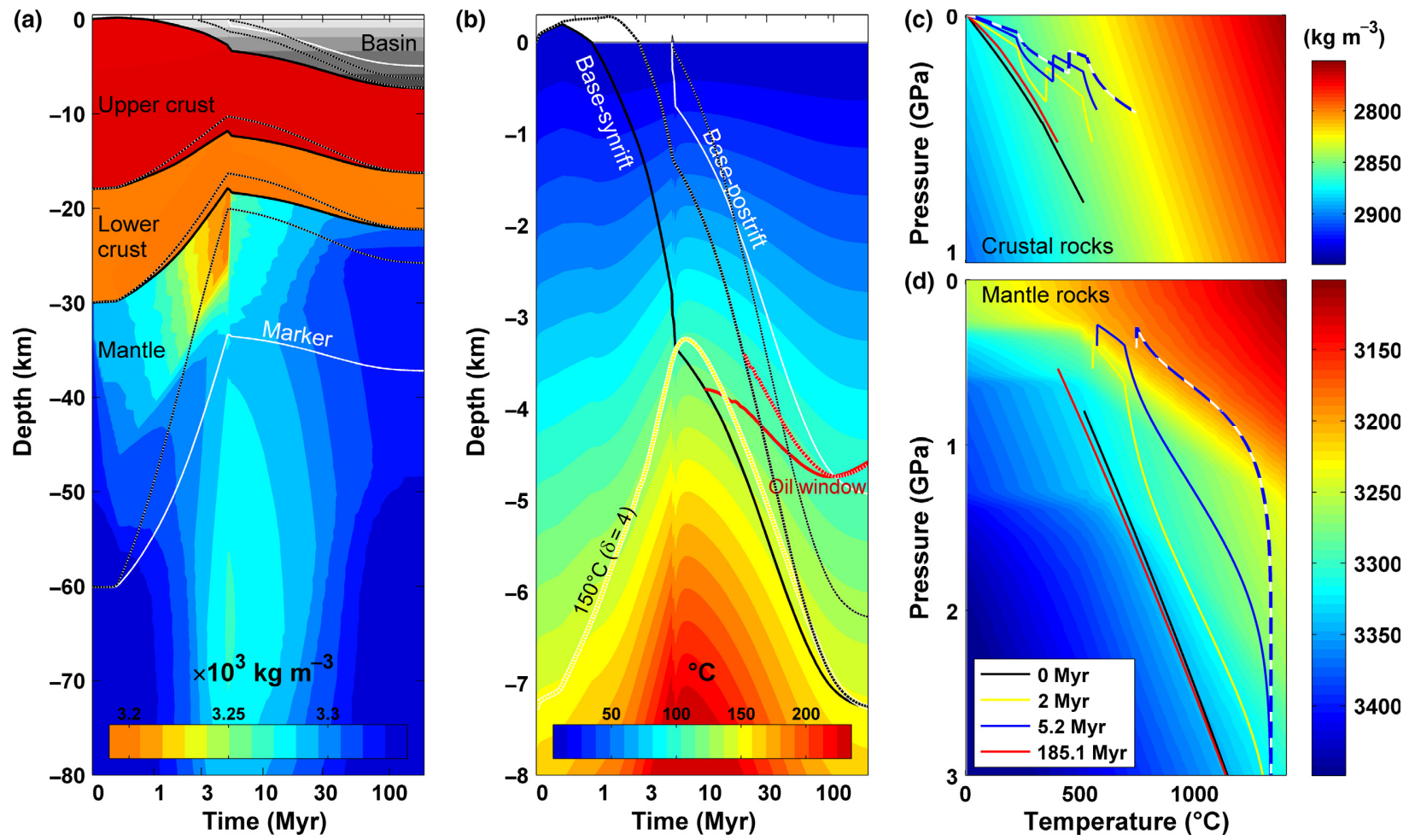

Fig. 6. Evolution of the mechanical model with mantle density (d) controlled by mineral phase transitions. See Fig. 3 for other details of design.

increases relative to the post-rift. The reason for this is that in the models with a slower rift less heat is advected to the shallower parts of the model and counteracted by synrift diffusion of the heat. This reduces the potential for post-rift thermal subsidence. The results in Fig. 7 are compatible with Jarvis \& McKenzie (1980) who found that the original McKenzie model with instantaneous thinning is a good approximation for systems with rift durations up to $20 \mathrm{Myr}$. The almost linear scaling of $\lambda$ with rift duration can be used as a guideline to extrapolate our other model results where we kept a rift duration of 5 Myr.

\section{Uplift}

Uplift during the synrift is a rather intriguing observation in a system that undergoes active extension. However, even the original, uniform stretching McKenzie model is capable of producing uplift if the initial crust is extremely thin $(<15 \mathrm{~km}$, Fig. 8). If the mantle is thinned more than the crust then uplift results also for thicker crust. However, no uplift occurs for crust of initial thickness $30 \mathrm{~km}$ or more within this model (Royden \& Keen, 1980).

Kaus et al. (2005) demonstrated that uplift is also possible in uniform stretching models when mantle phase transitions are accounted for. They inferred that the minimum stretching factor for uplift to occur must be $>3$. Interestingly, the uplift reported by Royden \& Keen (1980) model occurs in the early synrift, whereas the one observed by Kaus et al. (2005) occurs in the late synrift stage.
The standard models of our study do not result in uplift as long as we consider uniform stretching. The reason for this is that our stretching factor is only 2 . In addition, we use a mantle phase transition map that exhibits less extreme differences between the different stability fields than the one employed by Kaus et al. (2005). Standard models with differential stretching $\delta=4$ do result in a small $(c a .3 \mathrm{~m})$ uplift if mantle phase transitions are considered (Fig. 4). This amount of uplift is so small that the introduction of erosion does not have a substantial effect ( $c a .5 \mathrm{~m}$ uplift). Extreme differential stretching $(\delta \geq 6)$ of such models may increase uplift, but only up to minor amount (50-70 m, Fig. 8).

Uplift is the parameter that best illustrates the importance of considering mechanics in our models. Even the model with density only linearly depending on pressure and temperature shows $110 \mathrm{~m}$ of uplift, whereas the model with mantle phase transitions results in $200 \mathrm{~m}$ of uplift. Curiously, the additional consideration of differential thinning does not alter these values significantly. Conversely, the introduction of erosion introduces a positive feedback loop and uplift amounts of more than 600 and $1100 \mathrm{~m}$, respectively.

The main contribution to the uplift stems from our consideration of nonlithostatic pressure. When rifting starts, the system goes into tension and underpressure develops especially in the strongest part of the model (Fig. 2). This leads to a reduced average density of the lithospheric column and related uplift in both models 
Table 1. Comparison of the key parameters of the different models.

\begin{tabular}{|c|c|c|c|c|}
\hline \multirow{2}{*}{$\begin{array}{l}\text { Models } \\
P T \text { dependence of density }\end{array}$} & \multicolumn{2}{|c|}{ Standard } & \multicolumn{2}{|c|}{ Mechanics } \\
\hline & Linear & MPT & Linear & MPT \\
\hline Shear heating and underpressure & No & No & Yes & Yes \\
\hline \multicolumn{5}{|l|}{ Results ( $\delta=1$, no erosion) } \\
\hline Thickness of synrift sediments, $\mathrm{km}$ & 4.53 & 3.14 & 4.25 & 2.34 \\
\hline Thickness of post-rift sediments, km & 2.67 & 4.06 & 2.95 & 4.85 \\
\hline Syn-/post-rift sediments ratio, $\lambda$ & 1.7 & 0.77 & 1.44 & 0.48 \\
\hline Max. elevation, km & 0 & 0 & 0.11 & 0.2 \\
\hline \multicolumn{5}{|l|}{ Results ( $\delta=4$, no erosion $)$} \\
\hline Syn-/post-rift sediments ratio, $\lambda$ & 0.83 & 0.19 & 0.77 & 0.16 \\
\hline Max. elevation, km & 0 & 0.003 & 0.13 & 0.28 \\
\hline \multicolumn{5}{|l|}{ Results $(\delta=1$, infinitely fast erosion)* } \\
\hline Syn-/post-rift sediments ratio, $\lambda$ & 1.7 & 0.77 & 1.48 & 0.52 \\
\hline Amount of erosion/max uplift of the basement, $\mathrm{km}$ & 0 & 0 & 0.62 & 1.15 \\
\hline \multicolumn{5}{|l|}{ Results $(\delta=4 \text {, infinitely fast erosion })^{*}$} \\
\hline Syn-/post-rift sediments ratio, $\lambda$ & 1.7 & 0.77 & 0.81 & 0.20 \\
\hline Amount of erosion/max uplift of the basement, $\mathrm{km}$ & 0 & 0.005 & 0.67 & 1.85 \\
\hline
\end{tabular}

Note that the erosion models, marked with $*$, result in a different total subsidence due to the erosion of crustal material, which leads to a different isostatic equilibrium.
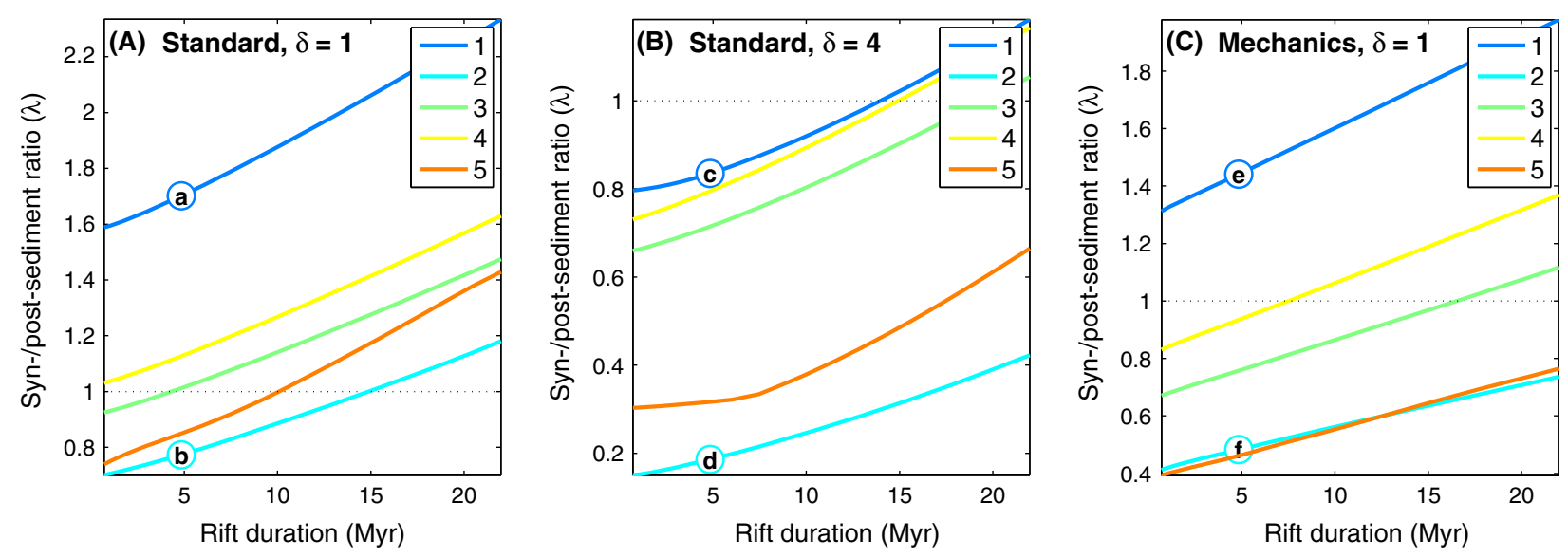

Fig. 7. Syn- to post-rift sediment thickness ratio for variable rates of active phase of rifting for different mantle density models: (1) linear pressure- and temperature-dependent density; (2) Hawaiian pyrolite of Simon \& Podladchikov (2008); (3) and (4) two compositions of Ronda peridotite (Frey et al., 1985; Simon \& Podladchikov, 2008) and (5) Hawaiian pyrolite of Kaus et al. (2005). Three different types of experiments are presented: (A) standard models with $\delta=1$ (see details of experiments (a) and (b) in Figs 3 and 4); (B) standard models with $\delta=4$ (see details of experiments (c) and (d) in Figs 3 and 4, stippled lines); (C) mechanical models with $\delta=1$ (see details of experiments (e) and (f) in Figs 5 and 6).

with and without mineral phase transitions as even our simplest model considers the pressure dependence of density.

Similar to uplift due to differential thinning the phase of active uplift in our models is the early synrift. In the most extreme models sedimentation only becomes active towards the end of the synrift. However, even in these cases the resulting synrift to post-rift thickness ratio is almost the same compared to models without erosion, which is due to more rapid sedimentation over the remaining synrift.

We demonstrate how forces moving the rifting process lead to establishing of the underpressure, decrease in rock density and consequent uplift. The same way the end of intra-plate extension removes acting forces and increase pressure by removing underpressure, this phenomenon may be responsible for subsidence acceleration in the post-rift (Middleton, 1980; Hamdani et al., 1994). We did not give this phenomenon special consideration and leave it to future study.

Our study presents a mechanism of early synrift uplift caused by density changes in the underpressurised mantle. Synrift uplift may be related to other mechanisms, such as serpentinisation and partial decompression melting, which may dominate over the one suggested in this study under specific conditions. In contrast with the other mechanisms, the one suggested in our study has a much broader applicability range. 


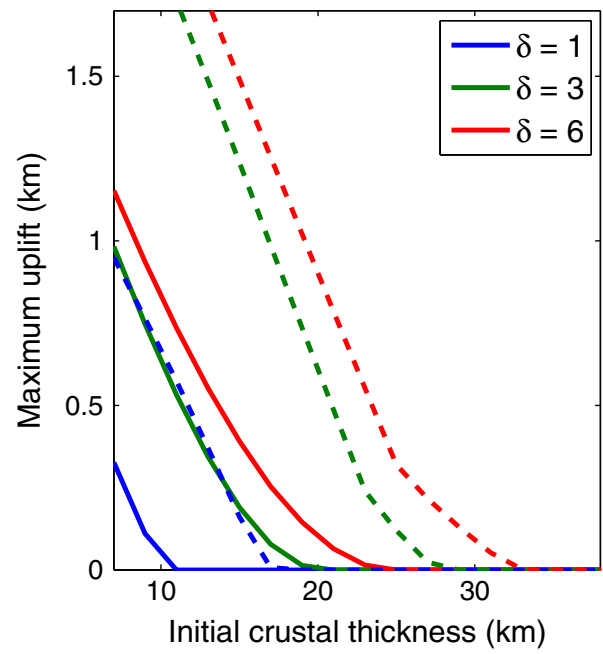

Fig. 8. Uplift as a function of initial crustal thickness and amount of differential thinning. The models considered here differ from the model of section 'Linear pressure dependence' (solid lines) and of section 'Mineral phase transitions' (dashed lines) only by initial thickness of the crust. Note that the dependency on differential thinning is lost with increasing $\delta$ and that the asymptotic maximum is essentially reached with $\delta=6$.

\section{Temperature and source rock maturity}

The effect of thinning the crust and the lithospheric mantle on temperature is to heat the overall system. However, if we focus only on the uppermost crust and the sediments then we can observe more differentiated details. The early synrift (0-2 Myr) is characterised by only minor temperature variations in the uppermost crust. This is followed by a phase of rift-related heating lasting from the middle/ late synrift to the early post-rift. The final stages of the model are then dominated by a cooling towards the burial-dominated equilibrium temperature configuration. If we follow the depth of individual isotherms through this model evolution we observe substantial changes, for example $c a .1 \mathrm{~km}$ for the $100{ }^{\circ} \mathrm{C}$ isotherm. This is relevant for modelling the temperature state in petroleum system analysis.

The picture drawn of the temperature evolution so far is an Eulerian one where the reference frame is depth and all models yield a similar overall development. If we analyse the depth of the oil window then we need to consider the (Lagrangian) path of individual sediment packages as vitrinite records the time-temperature evolution. The details of this depend on the rate of heating versus the rate of subsidence. In the models with density only linearly depending on pressure, the oil window $(\mathrm{Ro} \%=0.7$, Sweeney \& Burnham, 1990) is reached by the oldest sediments right at the synriftpost-rift transition at a depth of almost $5 \mathrm{~km}$ in the case of uniform stretching and $3.5 \mathrm{~km}$ in our differential stretching model. Over the next 5-10 Myr the depth of the oil window becomes progressively shallower, 4 and $3 \mathrm{~km}$, respectively, due to the input riftrelated heat. The final stages are dominated by burial and the depth of the oil window will be lowered 1.5$1 \mathrm{~km}$, respectively. The inclusion of mechanical effects has essentially no influence on the development of the oil window.

Conversely, the inclusion of mantle phase transitions substantially changes the oil window evolution. In the case of uniform stretching the oldest sediments do not reach the oil window before $10 \mathrm{Myr}$, that is $5 \mathrm{Myr}$ into the post-rift. As the rift related heat has started to diffuse away and due to post-rift sediment accumulation, the oil window deepens during next ca. $80 \mathrm{Myr}$. A minor shallowing towards the end of the model is caused by the long exposure to constant temperatures. Differential thinning moves the start of the oil window even farther into the post-rift (ca. $20 \mathrm{Myr}$ ), but with an initial occurrence at a shallower depth $(3.5 \mathrm{~km}$ vs $4 \mathrm{~km})$ due to the additional heat of the differential stretching model. The final path of the oil window is identical in all models as it is entirely burial controlled.

\section{Relative importance of underpressure and shear heating}

Our mechanical models consider two separate mechanical components, that is underpressure and shear heating. To not further increase the numbers of (sub)models to discuss, we have refrained from studying them separately. Underpressure is clearly the dominant one of the two and plays a key role for uplift. Shear heating is similar to differential stretching as both bring additional heat into the system. However, it must be kept in mind that our mechanical model is a simplified, semi-kinematic 1D model. It is known that shear heating may play a crucial role in mechanically self-consistent models where shear heating may determine the overall style of deformation (e.g. Minakov et al., 2013).

From a mechanical point of view both underpressure and shear heating must be considered. There are still ongoing discussions regarding the importance of these components, but mounting evidence indicates that they cannot be ignored (Hartz \& Podladchikov, 2008; Gerya, 2015). This study is another manifestation of this observation.

\section{Robustness}

We only present a small fraction of the more than $10^{5}$ models that we run with different initial conditions, boundary conditions, rheological and thermal parameters, mineral phase transition models and rift duration. Perhaps of particular interest is that our results do not depend strongly on rheological input values. For example, even if we limit shear heating and tectonic underpressure by cutting rock strength to half, the models still return the same overall tendencies.

The thermal properties of the sediments play a crucial role in the basin development. A constant thermal conductivity of $3 \mathrm{~W} \mathrm{~m}^{-1} \mathrm{~K}^{-1}$ may be considered as somewhat high. Decreasing the sediment conductivity to 
$2 \mathrm{~W} \mathrm{~m}^{-1} \mathrm{~K}^{-1}$ leads to an increased sediment blanketing effect resulting in a $10 \%$ increase of $\lambda$ (thicker synrift sediments) and an oil window that is approximately $1 \mathrm{~km}$ shallower. These quantitative changes do not invalidate the conclusions of our study.

Although we consider the presented results representative, it is clear that every model is limited in its applicability, such as already mentioned in the previous section. Possibly the strongest assumption that influences most of our results is that we assume infinitely fast sedimentation. It is clear that if we would limit the sedimentation rate we could arbitrarily alter the synrift and post-rift thicknesses within the bounds of the available accommodation space. This needs to be considered when applying our results to basins that show signs of sediment starvation.

The model presented here considers garnet-spinelplagioclase phase transitions of peridotite, most abundant phases covering most of the natural conditions. Hyperextended continental margins may lead to serpentinisation of wet peridotite causing extreme volume change and uplift (Pérez-Gussinyé et al., 2006; Peron-Pinvidic et al., 2013). In this study we do not present examples of such extreme lithospheric thinning and thus the mantle does not experience serpentine stability conditions. Additional tests show that this effect could be important, however, such extreme scenarios lie outside of our purpose of finding general causes of synrift uplift.

\section{CONCLUSIONS}

In this study we bring together extensions of the wellknown McKenzie model, that is finite rift duration, differential thinning and mantle mineral phase transitions, and complement these with a simplified mechanical model that includes the effects of underpressure and shear heating. We study the effects of the individual components and their combination on the temperature state of the lithosphere, crust and sediments, parameters that characterise the overall basin structure such as the synrift to post-rift thickness ratio and uplift, as well as the depth and timing of oil generation. Our results show that the picture of the 'standard' rift basin with a dominant synrift followed by a smaller post-rift may be the exception rather than the norm.

The question arises to which components of our model are most important. They all have key control over certain relevant parameters but do not influence everything. Both mantle mineral phase transitions and differential thinning drastically reduce the synrift package thickness and correspondingly increase the post-rift. Combining the two mechanisms results in almost no synrift record. If we, on the other hand, take the oil window as the parameter of interest then we see that they have a different effect. Whereas differential thinning changes the details of the location and amplitude of the curve illustrating the oil window, mantle mineral phase transitions change the overall behaviour. Introducing the mechanical effects of underpressure and shear heating has almost no effect on the synrift to post-rift thickness ratio, but introduces early synrift uplift in both models with and without mineral phase transitions. If we, in addition, allow erosion then the uplift magnitudes are massively amplified. The introduction of erosion, on the other hand, has essentially no effect on the synrift to post-rift thickness ratio. Therefore, all model components are relevant, especially in an integrated approach where it does not suffice to only analyse and explain one parameter.

Sedimentary basins to which our models are compatible can be found worldwide. The North-East Atlantic is a prime example with thin synrift and thick post-rift packages related to the last large rift event in the late Jurassic and the super-regional Base Cretaceous unconformity intimately tied to the same event. In this area it is evident that lower Cretaceous sediments often are missing above the rift zone, and that dramatic subsidence first initiates long after the rift maxima, as predicted by the models presented here.

\section{ACKNOWLEDGEMENTS}

Financial support from Det norske oljeselskap and the Norwegian Research Council through a Centre of Excellence grant to the CEED is appreciated. This project was partly funded by a grant from $\mathrm{UiO}$ to PGP. Critical comments from C. Ebinger and two anonymous reviewers helped to improve the early version of the manuscript.

\section{CONFLICT OF INTEREST}

No conflict of interest declared.

\section{REFERENCES}

Beaumont, C., Keen, C.E. \& Boutilier, R. (1982) On the evolution of rifted continental margins: comparison of models and observations for the nova scotian margin. Geophys. F. Int., 70, 667-715.

Braun, J. \& Beaumont, C. (1989) A physical explanation of the relation between flank uplifts and the breakup unconformity at rifted continental margins. Geology, 17, 760-764.

Brekke, H., Sjulstad, H.I., Magnus, C. \& Williams, R.W. (2001) Sedimentary environments offshore Norway-an overview. Normegian Petrol. Soc. Spl. Publ., 10, 7-37.

Burov, E. \& Gerya, T. (2014) Asymmetric three-dimensional topography over mantle plumes. Nature, 513, 85-89.

Byerlee, J. (1978) Friction of rocks. Pure Appl. Geophys., 116, 615-626.

Carter, N.L. \& Tsenn, M.C. (1987) Flow properties of continental lithosphere. Tectonophysics, 136, 27-63.

Chopra, P.N. \& Paterson, M.S. (1981) The experimental deformation of dunite. Tectonophysics, 78, 453-473.

Christiansson, P., Faleide, J. \& Berge, A. (2000) Crustal structure in the northern North Sea: an integrated geophysical study. Spl. Publ. Geol. Soc. Lond., 167, 15-40. 
Ebinger, C.J., Karner, G.D. \& Weissel, J.K. (1991) Mechanical strength of extended continental lithosphere: constraints from the western rift system, East Africa. Tectonics, 10, 12391256.

Frey, F.A., Suen, C.J. \& Stockman, H.W. (1985) The ronda high-temperature peridotite - geochemistry and petrogenesis. Geochim. Cosmochim. Acta, 49, 2469-2491.

Gabrielsen, R.H., KyrkJebø, R., Faleide, J.I., FJeldskaar, W. \& KJENnERUD, T. (2001) The cretaceous post-rift basin configuration of the Northern North Sea. Petrol. Geosci., 7, 137154.

GERYA, T. (2015) Tectonic overpressure and underpressure in lithospheric tectonics and metamorphism. 7. Metamorph. Geol., 33, 785-800.

Hamdani, Y., Mareschal, J.C. \& Arkani-Hamed, J. (1994) Phase change and thermal subsidence of the williston basin. Geophys. F. Int., 116, 585-597.

Hantschel, T. \& Kauerauf, A.I. (2009) Fundamentals of Basin and Petroleum Systems Modeling. Springer-Verlag, Berlin, Heidelberg.

Hartz, E.H. \& PodladchiKov, Y.Y. (2008) Toasting the jelly sandwich: the effect of shear heating on lithospheric geotherms and strength. Geology, 36, 331-334.

Hartz, E.H., Andresen, A., Hodges, K.V. \& Martin, M.W. (2001) Syncontractional extension and exhumation of deep crustal rocks in the east greenland caledonides. Tectonics, 20, $58-77$.

Herzberg, C., Condie, K. \& Korenaga, J. (2010) Thermal history of the earth and its petrological expression. Earth Planet. Sci. Lett., 292, 79-88.

Huismans, R.S. \& Beaumont, C. (2002) Asymmetric lithospheric extension: the role of frictional plastic strain softening inferred from numerical experiments. Geology, 30, 211-214.

Jarvis, G.T. \& McKenzIE, D.P. (1980) Sedimentary basin formation with finite extension rates. Earth Planet. Sci. Lett., 48, $42-52$.

Kaus, B.J.P., Connolly, J.A.D., Podladchikov, Y.Y. \& SchMaLholz, S.M. (2005) Effect of mineral phase transitions on sedimentary basin subsidence and uplift. Earth Planet. Sci. Lett., 233, 213-228.

Keir, D., Bastow, I.D., Whaler, K.A., Daly, E., Cornwell, D.G. \& Hautot, S. (2009) Lower crustal earthquakes near the ethiopian rift induced by magmatic processes. Geochem. Geophys. Geosyst., 10, Q0AB02.

Kyrkjebø, R., Gabrielsen, R. \& Faleide, J. (2004) Unconformities related to the jurassic-cretaceous synrift-post-rift transition of the Northern North Sea. 7. Geol. Soc., 161, 1-17.

ManckTelow, N.S. (2008) Tectonic pressure: theoretical concepts and modelled examples. Lithos, 103, 149-177.

McKenzie, D. (1978) Some remarks on development of sedimentary basins. Earth Planet. Sci. Lett., 40, 25-32.

Middleton, M.F. (1980) A model of intracratonic basin formation, entailing deep crustal metamorphism (subsidence). Geophys. F. Roy. Astronom. Soc., 62, 1-14.

Minakov, A.N., Podladchikov, Y.Y., Faleide, J.I. \& HuisMANS, R.S. (2013) Rifting assisted by shear heating and formation of the lomonosov ridge. Earth Planet. Sci. Lett., 373, $31-40$.

Pérez-Gussinyé, M., Reston, T. \& Morgan, J.P. (2001) Serpentinization and magmatism during extension at non-volcanic margins: the effect of initial lithospheric structure. Geol. Soc. Lon. Spl. Publ., 187, 551-576.
Pérez-Gussinyé, M., Morgan, J.P., Reston, T.J. \& Ranero, C.R. (2006) The rift to drift transition at non-volcanic margins: insights from numerical modelling. Earth Planet. Sci. Lett., 244, 458-473.

Peron-Pinvidic, G., Manatschal, G. \& Osmundsen, P.T. (2013) Structural comparison of archetypal atlantic rifted margins: a review of observations and concepts. Mar. Pet. Geol., 43, 21-47.

Petrini, K. \& Podladchikov, Y. (2000) Lithospheric pressuredepth relationship in compressive regions of thickened crust. 7. Metamorph. Geol., 18, 67-77.

Petrini, K., Connolly, J.A.D. \& Podladchikov, Y.Y. (2001) A coupled petrological-tectonic model for sedimentary basin evolution: the influence of metamorphic reactions on basin subsidence. Terra Nova, 13, 354-359.

Podladchikov, Y.Y., Poliakov, A.N.B. \& Yuen, D.A. (1994) The effect of lithospheric phase transitions on subsidence of extending continental lithosphere. Earth Planet. Sci. Lett., 124, 95-103.

Ren, S., Faleide, J.I., Eldholm, O., Skogseid, J. \& Gradstein, F. (2003) Late cretaceous-paleocene tectonic development of the Nw Vøring basin. Mar. Pet. Geol., 20, 177-206.

Rowley, D.B. \& Sahagian, D. (1986) Depth-dependent stretching - a different approach. Geology, 14, 32-35.

Royden, L. \& KeEN, C.E. (1980) Rifting process and thermal evolution of the continental margin of eastern canada determined from subsidence curves. Earth Planet. Sci. Lett., 51, 343-361.

Schmalholz, S.M., Medvedev, S., Lechmann, S.M. \& PodLADCHIKOV, Y.Y. (2014) Relationship between tectonic overpressure, deviatoric stress, driving force, isostasy and gravitational potential energy. Geophys. F. Int., 197, 680-696.

Sclater, J.G. \& Christie, P.A.F. (1980) Continental stretching - an explanation of the post-mid-cretaceous subsidence of the central north-sea basin. 7. Geophys. Res., 85, 3711-3739.

Sclater, J.G., Royden, L., Horvath, F., Burchfiel, B.C., Semken, S. \& Stegena, L. (1980) The formation of the intracarpathian basins as determined from subsidence data. Earth Planet. Sci. Lett., 51, 139-162.

Simon, N.S.C. \& Podladchikov, Y.Y. (2008) The effect of mantle composition on density in the extending lithosphere. Earth Planet. Sci. Lett., 272, 148-157.

Spadini, G., Robinson, A.G. \& Cloetingh, S.A.P.L. (1997) Thermomechanical modeling of black sea basin formation, subsidence, and sedimentation. AAPG Memoir, 68, $19-38$.

SURLYK, F. (1991) Sequence stratigraphy of the jurassic-lowermost cretaceous of east greenland (1). Am. Assoc. Pet. Geol. Bull., 75, 1468-1488.

SweEney, J.J. \& Burnham, A.K. (1990) Evaluation of a simple model of vitrinite reflectance based on chemical kinetics (1). Am. Assoc. Pet. Geol. Bull., 74, 1559-1570.

Ulmer, P. \& TrommsdorfF, V. (1995) Serpentine stability to mantle depths and subduction-related magmatism. Science, 268, 858-861.

Walker, I.M., Berry, K.A., Bruce, J.R., BystøL, L. \& SNOW, J.H. (1997) Structural modelling of regional depth profiles in the vøring basin: implications for the structural and stratigraphic development of the norwegian passive margin. $\mathcal{F}$. Geol. Soc., 154, 537-544.

Wangen, M. (1995) The blanketing effect in sedimentary basins. Basin Res., 7, 283-298. 
Weissel, J.K. \& Karner, G.D. (1989) Flexural uplift of rift flanks due to mechanical unloading of the lithosphere during extension. F. Geophys. Res., 94, 13919-13950.

WERniCKe, B. (1985) Uniform-sense normal simple shear of the continental lithosphere. Can. 7. Earth Sci., 22, 108125.

White, N. \& McKenzie, D. (1988) Formation of the" Steer's Head" geometry of sedimentary basins by differential stretching of the crust and mantle. Geology, 16, 250-253.

Wilks, K.R. \& Carter, N.L. (1990) Rheology of some continental lower crustal rocks. Tectonophysics, 182, $57-77$.
Wolfenden, E., Ebinger, C., Yirgu, G., Renne, P.R. \& KELLEY, S.P. (2005) Evolution of a volcanic rifted margin: southern red sea, Ethiopia. Geol. Soc. Am. Bull., 117, 846-864.

Yamasaki, T. \& NAKada, M. (1997) The effects of the spinelgarnet phase transition on the formation of rifted sedimentary basins. Geophys. F. Int., 130, 681-692.

Ziegler, P.A. \& Cloetingh, S. (2004) Dynamic processes controlling evolution of rifted basins. Earth Sci. Rev., 64, 1-50.

Manuscript received 15 fuly 2015; In revised form 28 Fanuary 2016; Manuscript accepted 2 February 2016. 